\title{
Medical Technology Management and Patient Safety
}

\author{
Mana Sezdi \\ Istanbul University \\ Turkey
}

\section{Introduction}

Health organizations are businesses in technological intensity. All hospitals contain several technologies such as magnetic resonance (MRI) technology, laser technology, X-ray technology, RF technology, micro-camera systems, ..etc. The management of these systems that is called as "biomedical technology" is not easy. The basic principle of biomedical technology management is based on safety. Especially, because the affected ones by the bad management are patients, the importance of the biomedical technology management is better understood. At this point, "patient safety" comes to the foreground. Patient safety is the most critical international issue because of countless bad-practice events also related to biomedical technology management.

Patient safety that is one of the basic components of quality of care is defined briefly as the patient is not damaged and is not exposed to medical errors. The main target in the patient safety applications is the establishment of a system to protect the patient from potential damage and to eliminate the possibility of error.

Health organizations should create the safe, functional and supportive environment for patients, relatives and employees. To achieve this goal, the physical environment, medical and other equipment and human resources must be managed effectively. Systematic steps in this regard will result in the expansion of patient safety practices. The main priority of accreditation programs is to ensure the safety of patients and employees. More than $50 \%$ of Joint Commission International accreditation standards are related to patient safety.

For quality studies focused on patient safety in health establishments, the safe use of medical technology is necessary. When the medical devices' qualifications, locations and preventive maintenance applications are considered, it is seen that the safety of medical devices is the most important issue to improve patient safety.

Factors affecting the patient directly in a hospital environment are medical devices and device users. High-tech medical devices that are used for the purpose of both diagnosis and treatment are the most important determining factors about patient safety. The design of medical devices, the interactions with each other and insufficient training of users are negative impacts on patient safety.

If these problems are examined one by one, it would be appropriate to consider the systematic errors that are impressive on patient safety. In this study, all these effects mentioned below will be handled one by one. 
- Interactions between medical devices

- Sterilization

- $\quad$ Re-use of single use devices

- Medical device accidents and user errors

- The classification of clean room, particle measurement

- Radiation safety

- Electrical safety and

- Performance measurements of medical devices.

There are a number of recent studies about patient safety. Some of them are the surveys of medical device accidents and user errors (Carol, 2003; Hijazi, 2011; Brennan, 1991; Sawyer, 1997; Sezdi, 2009a). Some of them are focused on only electrical safety (Barbosa et al., 2010; Osman et al., 1996; Chakrabartty et al., 2010; Bakes, 2007; Sezdi, 2009b), whereas the others examined both the sterilization and reusage of single use devices related to the patient safety (Yoleri, 2011; Rice et al., 2009; Quirk, 2002; Northrup, 2000; Day, 2004; Koh, 2005; Buchdid Amarante, 2008; Hailey et al., 2008). There are also studies that explain the classification of clean rooms by measuring particles (Sezdi, 2009c). It is essential to collect all issues in order to ensure the safety management of medical devices.

\section{Interactions between medical devices}

The medical devices affect each other because of several interactions. Particularly, in the environments where many medical devices are connected to the patient such as operating rooms, intensive care services,...etc., there may be interaction between the devices. Especially, because of interference from radiofrequency energy that is called radiofrequency interference (RFI), there are several failures that cause to serious injuries and death. The reasons of the radiofrequency interference are the increasing numbers of electronically controlled medical devices with inadequate electronic protection against RFI and the increasing numbers of radiofrequency sources in the environment.

Mobile phones that are today's indispensable communication tools, enhance the potential for radiofrequency interference and have negative impacts on medical devices especially on pacemakers, apnea monitors and ventilators. The impacts of mobile phones with different frequency and UHF radio frequency receiver / transmitter on ventilators were examined in many statistical studies and a highly interaction was observed (Gilligan et al., 2000; PMDA, 2006; Lawrentschuk et al., 2004, Tan et al., 2001; Bassen, 1998; FDA, 1997; Carranza et al., 2011; Pressly, 2000; Hans et al., 2008).

For example, when a physiological monitor is used in conjunction with an electrosurgical unit, the ECG or arterial blood pressure waveform disturbs. Burns under the ECG electrodes may occur. During cardiac catheterization, ventricular fibrillation may occur.

If an anesthesia machine is used in magnetic resonance room, it creates the image distorts because its metal parts cause magnetic effect.

For the elimination of the negativity, the electromagnetic compatibility (EMC) standards related to medical devices and their placement in hospitals should be created. During new devices are purchased, electromagnetic compatibility should be considered. 


\section{Sterilization}

Sterilization is the other important issue for patient safety because all materials in contact with mucous membranes must be sterile. Sterilization is a process to destroy all microorganisms found in or on a substance. In 1995, sterilization is defined by Association for the Advancement of Medical Instrumentation (AAMI) as a process intended to remove or destroy all viable forms of microbial life, including bacterial spores, to achive an acceptable sterility assurance level (AAMI, 1995). Sterility Assurance Level (SAL) can be defined as the probability to remain only one live sport when sterilization process is repeated a million times.

Although there are a lot of sterilization method, the most widely used sterilization method in a hospital environment is heat sterilization. The action mechanism of heat sterilization is to destroy proteins in the cell directly. In heat sterilization, the effective factors are temperature, time of the heat effect, the degree of moisture, the water content of microorganisms, $\mathrm{pH}$ and osmotic pressure.

Heat sterilization is classified as dry heat sterilization and steam sterilization. For effective dry heat sterilization, $175{ }^{\circ} \mathrm{C}$ process of 1 hour or $140{ }^{\circ} \mathrm{C}$ process of 3 hours is sufficient. Because of lack of humidity in environment, sterilization takes longer. In this manner, glass and metal instruments, oil and dust are sterilized.

Steam sterilization is performed at $121{ }^{\circ} \mathrm{C}$ under $1.5 \mathrm{~atm}$ pressure for 15 minutes. Usually, the materials that do not deteriorate under heat and pressure, are made sterile. For steam sterilization, the tool called autoclave is used. The basic principle is that every point of the material to be sterilized comes into contact with saturated water vapor in adequate time. For this reason, there are some principles to be followed during the packages are created and are placed autoclave. These include:

- The material to be sterilized must be cleaned by applying pre-cleaning process and it must be free from visible dirt.

- $\quad$ Packet size must comply with the size of the autoclave.

- Packaging material must be able to allow access and exit of steam.

- Non-woven packaging materials (plastic polymers, cellulose fibers and a specially produced paper) should be preferred because of their small pores.

- Labels reporting the contents of the package must be affixed on the packages.

- Date of sterilization, shelf life and department must be written on the label.

- Labeling process should not hurt the package.

- Packages should be placed loosely in the autoclave to contact the steam at each points.

- The materials that are not required packaging should be placed in the appropriate baskets or containers.

- $\quad$ The tubes filled with fluid material to be sterile must not be loaded completely.

- For the sterilization of materials in screw cap bottles, the caps should be loosened.

Material in the packages after the sterilization process must remain sterile until used. Sterile exposure time depends on the quality of packaging material, storage conditions, transfer conditions and the amount of materials. To maintain sterility after sterilization of the material, the considerations are as follows:

- Sterile equipment in case of moving and storing a long period of time, should be covered with a clean dust cloth. 
- Sterile storage area must be close to sterilization area and entry to this room must be limited.

- Storage area must have a ventilation system for the appropriate temperature and humidity conditions. Temperature should be $18-22{ }^{\circ} \mathrm{C}$ and humidity should be $35-50 \%$.

- Packages should be kept in closed cabinets.

- If there is a damage on the package after sterilization, the material in the package should not be considered sterile.

In health care facilities, the devices that require more attention are sterilization devices. Because the materials and products in almost every department of the hospital have to be sterilized, sterilization devices and process must be controlled in intensity (Rutala et al., 2004; Dubois, 2002; McDermott, 2010; Kelkar et al., 2004). There are international standards in order to conduct inspection of the sterilization process. The standard of ANSI / AAMI ST79:2006 "Comprehensive guide to steam sterilization sterility assurance in health care facilities" recommends developing and implementing procedures for sterilization (ANSI/AAMI ST79, 2006). Sterility control is carried out in 3 main groups as physical control, chemical control and biological control.

Physical control is the control whether the autoclave unit works at proper temperature, pressure and time, or not. It is necessary to control the indicators of the device by the user before each use, and to perform maintenance service and validations by the biomedical staff periodically. Physical control gives us only information about the operation of the device, no information about the success of sterilization. Special designed temperature and pressure dataloggers are used for physical control of autoclaves (Figure 1). These are resistant to high temperature and pressure.
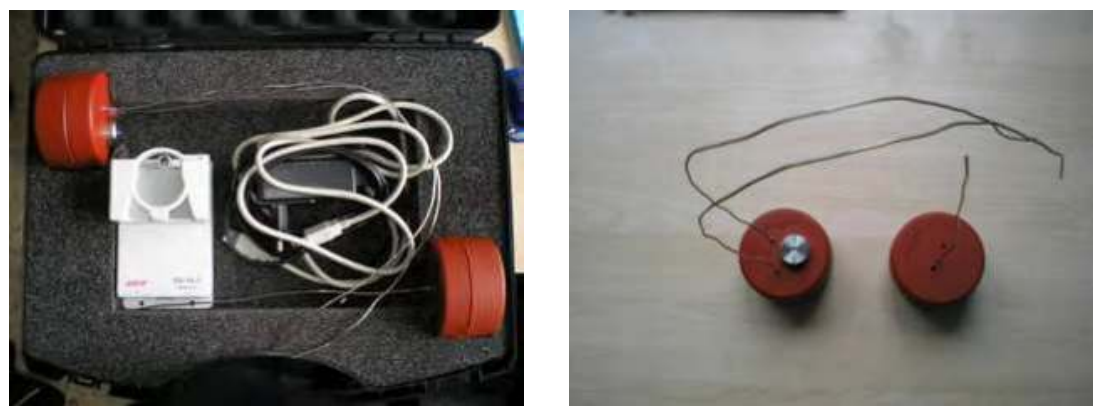

Fig. 1. Temperature and pressure dataloggers for physical control of autoclave (Yoleri, 2011)

As an example, the results of the physical control of an autoclave for the sterilization conditions of $121^{\circ} \mathrm{C}, 1,5 \mathrm{~atm}$ and 15 minutes, can be seen in Figure 2. 


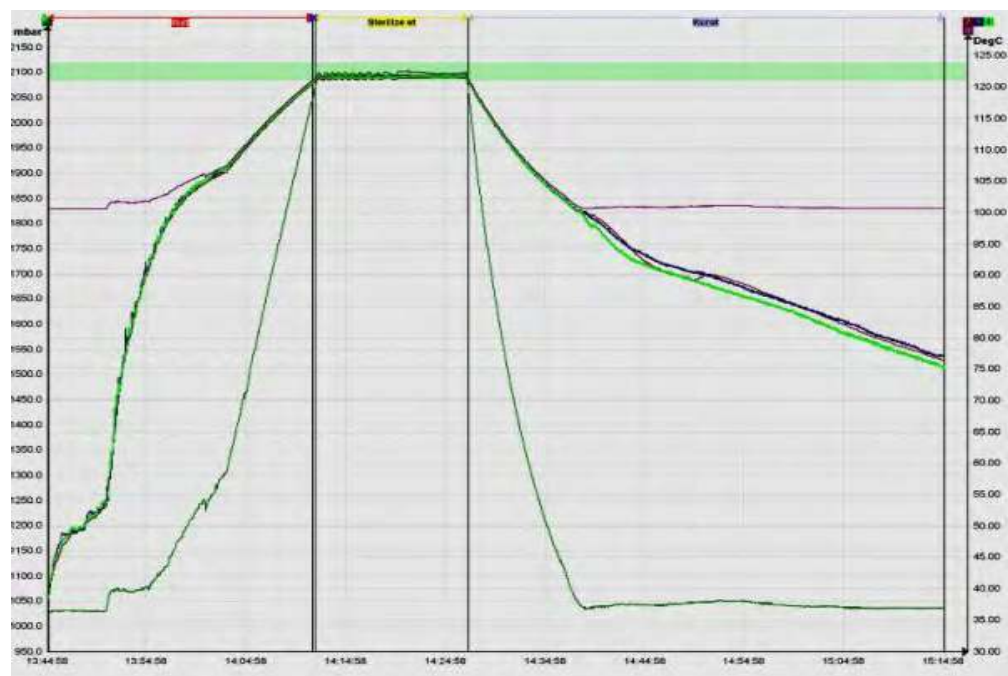

Fig. 2. The measurement results for the sterilization conditions of $121^{\circ} \mathrm{C}, 1,5 \mathrm{~atm}$ and 15 minutes (Yoleri, 2011). Sterilization process generates where the fixed curve during maximum pressure and max temperature.

Chemical indicators are used for chemical control. Chemical indicators are indicators which give information about the sterilization process by changing their color in response to chemical or physical conditions or changing from solid phase to liquid phase. A positive result on a chemical process indicator does not mean that the material is sterile, it shows that the required parameters of the sterilization process are fully implemented.

The mostly used chemical indicators are Bowie-Dick test apparatus. Bowie-Dick test apparatus consist of a series of vapor permeation layer barriers. A complete color change indicates the sufficient steam penetration (Figure 3(a), 3(c)). If the color change is nonuniform or there is no any color change, it means that autoclave has an air suspension failure (Figure 3(a), 3(b)) and it must be controlled.

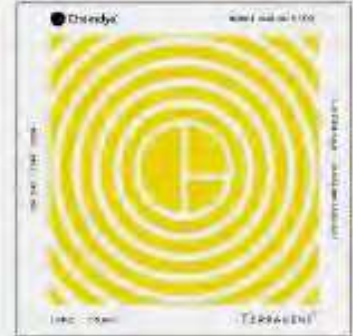

(a)

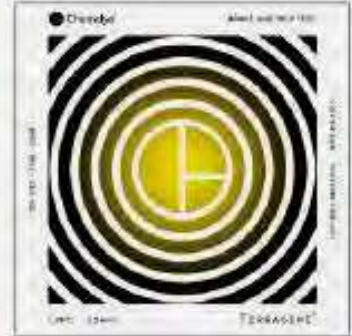

(b)

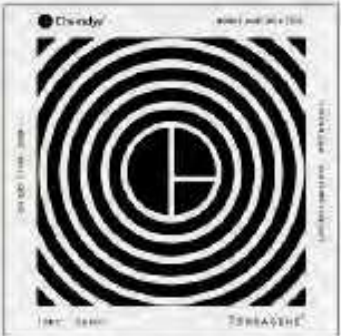

(c)

Fig. 3. The color changes on Bowie-Dick test apparatus (a) apparatus before application (b) non-uniform color change indicates insufficient steam penetration (c) uniform color change from yellow to black indicates sufficient steam penetration (http://www.scu.com.tr/BOWIE\&DICK\%20TEST\%20PAKET\%C4\%B0.pdf) 
Biological indicators are used for biological control. In biological indicators, there are bacteria spores, known as the most resistant to sterilization. In the packet, biological indicators are placed in the points that are thought as the most difficult points for sterilization process. After sterilization, whether biological death has been ensured or not, is controlled by applying reproduce test.

Association for the Advancement of Medical Instrumentation (AAMI) suggests that the sterilized material to be implanted into the body should not be used until the reception of biological indicator test results.

When properly used, sterilization can ensure the safe use of invasive and noninvasive medical devices. The method of sterilization depends on the use of the medical device. To perform sterilization techniques successfully, current sterilization guidelines must be followed.

\section{Re-use of single use devices}

The other important problem in patient safety is the uncontrolled reuse of single use devices (SUDs). Although the single use devices are the devices that are used for one patient-one operation, it is possible to use them for second or more patient without any risk by applying the reprocessing technique. A "reprocessed device" is explained briefly as an original device that has previously been used on a patient and has been subjected to additional processing and manufacturing for the purpose of an additional single use on a patient (Rice et al., 2009). Reprocessing of medical devices may occur in a hospital or be contracted to a third-party reprocessing facility. About $25 \%$ of hospitals in the USA use reprocessed single-use devices in according to a survey by the Food and Drug Administration (FDA). 84\% of the hospitals use third-party reprocessors to sterilize the devices, while $16 \%$ of them reprocess the devices in hospital (Quirk, 2002).

The approval of the reuse of single use devices is taken from FDA who is the authorized foundation. The reason of this application is that the manufacturers determine generally their devices as single use although the device can be used again after reprocessing. Manufacturers qualify their devices as single use devices because they want more production and more gain, and they want to launch their devices immediately without FDA approval because FDA approval time for reusable devices takes more time and manufacturers do not want to wait for a long time. Also, the manufacturer is not responsible to prove that a device can not be reprocessed. Because of this, although manufacturers say that the quarantee of working correctly of the reprocessed devices can not be given, FDA say that reprocessing is safe if FDA's requirements are performed (Northrup, 2000).

There are many studies about reusing of single-use devices. Some studies show that the reuse of SUDs is potentially safe and effective with reprocessing protocols and standards, while others do not recommend reprocessing and reuse because of the faulty devices (Day, 2004; Koh, 2005; Buchdid Amarante, 2008).

The FDA claims that the reprocessed device must be substantially equivalent to newly manufactured devices (Emergency Care Research Institute, 2006). It recommends that a medical device can not be reprocessed succesfully unless it can be cleaned, sterilized and function tested. Cleaning means removal of visible contaminants including body waste, body 
fluids, dirt, dust, etc. Sterilizing means meeting of domestic and international sterilization standards. Function tests verify that a device will perform as intended (Selvey, 2001).

Food and Drug Administration (FDA) has developed a list of known reprocessed SUDs (FDA, 2000). The list includes surgical saw blades, surgical drills, laparoscopy scissors, orthodontic braces, electrophysiology catheters, electrosurgical electrodes, respiratory therapy and anesthesia breathing circuits, endotracheal tubes, balloon angioplasty (PTCA) catheters and biopsy forceps. But, there is still uncertainty regarding the safety and effectiveness of the reuse of single use devices (Hailey et al., 2008).

Single use medical devices are classified by FDA according to the level and type of control needed to ensure that the devices are safe. Class I devices require the fewer controls, while Class II devices require "special controls". Class III devices are the most important class and are not adequate to reprocess.

Reprocessable Class I devices are devices that make contact and not penetrate intact skin. These are;

- General use surgical scissors,

- Non-electric biopsy forceps,

- Orthopedic chisels, knives and saw blades,

- Surgical curettes and gouges,

- Rasps.

Class II devices are devices that contact intact mucous membranes and not penetrate normally sterile areas of the body. These are;

- Laparoscopic scissors, clamps, dissecters and graspers,

- Compression sleeves,

- Recording and diagnostic EP catheters,

- Drills and burrs,

- Flexible snares.

Non-reprocessable Class III devices are devices that contact normally sterile tissue or body spaces during use. These are;

- Percutaneous and conduction tissue ablation electrodes,

- Transluminal coronary angioplasty catheters,

- Implanted infusion pumps.

During reusage of single use devices, two important risks should be considered. The first and the most important risk is the infection risk. The other risk is that the single use devices which are reused repeatedly, can not accomplish their function (Avitall et al., 1993, Rizzo et al., 2000, Zimerman et al., 2003). For example, in the reuse of catheters, some function risks may form. In the lumens, a contamination may occur, the catheters may slip and the distance between the electrodes may change. The worst of them, the electrodes may destroy the vessels by escaping from the catheter. Figure 4 shows the internal lumen of the reusable forceps having deformations after reprocessing.

To minimize the risks that affect patient safety directly, it must be required to obtain the information about the reuse of single use devices, to realize the applications standartly and to control the hospitals. 

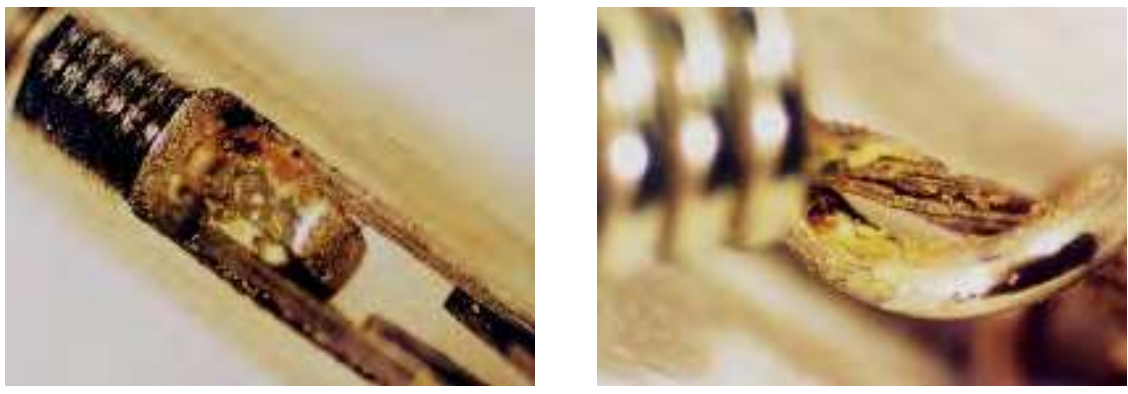

Fig. 4. Fig. 4. Photographs of the deformation in the lumen of the reusable forceps after reprocessing (Rizzo et al., 2000)

For patient safety, FDA proposed a strategy on reuse of single use devices. In the document that was published by FDA, the following steps are proposed to consider by hospital management (Henney, 2000).

- Regulation of third party reprocessors that reprocess SUDs in the same manner as the manufacturers of original equipment,

- Development of a device categorization system based on the risk level of SUDs,

- Writing comments on a draft list of frequently reprocessed SUDs,

- Providing information from the original equipment manufacturers on SUD's risk labels,

- Validation of procedure.

The testing procedures lead staff to develope specific protocols for cleaning, function testing and sterilizing of each reprocessed device. The testing procedures are known as validation.

Validation of reprocessing is classified as process validation and design validation.

- Process Validation controls the process consistently that produces a product meeting its predetermined specifications.

- Design Validation controls device specifications that conform with user needs and intended use.

A validation of reprocessing is necessary with respect to following safety issues (Popp et al., 2010):

- Physical safety (alteration of device's dimensions, weakening of components, poor performance, etc....)

- Chemical safety (absorption of cleaning agents, disinfectants, sterilization agents, toxic reactions, etc....)

- Biological safety (inadequate cleaning or disinfection of all surfaces, etc.....)

By doing validation studies, it can be proved that sterility will be achieved when the temperature and humidity parameters are used accurately. Because of this, validation studies must be established routine for each sterilization process. 


\section{Medical device accidents and user errors}

Medical device accidents and user errors are problems that must not be ignored and need to focus on, because accidents occurred in the health sector cause patient death, or at least cause an injury and disability. According to the Food and Drug Administration (FDA), in the United States about 1,3 million people are injured each year by accidents caused from medical devices (Carol, 2003; Rados, 2004). The FDA receives more than 95.000 medical device accident reports annually (Hijazi, 2011). In 2002 alone, FDA declared the medical device accidents of more than 111.000 causing serious injuries and deaths (Carol, 2003).

In a study performed by Harward Medical Practice Study, it was explained that $70 \%$ of 30.000 medical device injuries are caused by medical device accidents while $27,6 \%$ of them are caused by pure negligence (Brennan, 1991).

Because the used devices are high-tech, accidents occur largely as a result of user error.

Many statistical studies show that user errors are not less. The user errors can be classified in related to hardware design, software design, components and alarms of devices.

The errors related to hardware include control/display arrangement errors. Especially, in the infusion pump display panel, the flow rate readout may be blocked from view. For example, the top of the 7 is blocked from view and it can be read as 1 (Sawyer, 1997).

Software-related design errors result generally from unfamiliar language, symbols, codes and functions that are hidden from the user. For example, in some cardiac output monitor alarm may be disabled without the operator's knowledge when the control buttons are pushed in a specific sequence (Sawyer, 1997).

The most common errors reported to FDA are improper installations of device accessories. Some commonly reported errors are tubing connected to the wrong port, loose connections and accidental disconnections. According to Medical Device Recall Reports, several injuries and deaths occurred because of the disconnections of the breathing tubes in the ventilators due to poor tube and connector design.

Alarm problems are false alarms, delayed alarms, too sensitive or insensitive alarms, inappropriate silencing and accidental disabling. There are many scenarios that cause patient death. Low alarm intensity, high ambient noise, low battery conditions, inappropriate alarm settings and other factors combine to create potentially dangerous situations.

The accidents in the anesthesia machine come the first in the medical accident list. The reason of the importance of the anesthesia machine accident is that the death of healthy patient that is operated for a basic problem is not accepted.

In operations, the electrosurgical unit may cause accidents because of the uncontrolled usage of patient electrode (damaged patient electrode or decreased patient contact). The other risks that might be caused from the electrosurgical unit, are the explosion of the anesthetic agent in the operation room and the possibility of the touching of the active electrode to the healthy tissues.

Fires that occur during operations are discussed as medical device accident. Although there are a lot of resources of the operating room fires, oxygen provider, area which collect 
ambient gas and the igniter are 3 points that should be considered. During the operation, each of 3 parameters is in the responsibility of different people in the operation team.

Oxygen provider system is controlled by anesthesiologist who monitors the patient during the operation. If too much oxygen, nitrous oxide, or other flammable gases accumulate under the drapes fabric used in the operation, a tiny spark may cause an explosion. To prevent the accumulation of oxygen or to control the amount of preparing solutions are the responsibility of nurse in the surgery, while the use of electrocautery or laser devices that could lead to the spark are under the control of the doctor. Because the 3 factors that could cause a fire during the operation are under the control of 3 different people, very good communication should be established in order to prevent fire. Lack of communication can cause a very big explosion or fire (AMN Healthcare, 2008).

There are many accidents that are caused from which MRI's magnetic field strongly pull all sorts of metal goods (scissors, hanger of saline physiology) near field (Figure 5). Although in some MR imaging centers, it is aimed to prevent such accidents by placing the metal detector at the entrance points, sometimes the cautions are skipped. In the patients, very rarely 2 or 3 degrees of skin burns resulting from contact with the magnetic field windings or cables may be observed (Sezdi, 2009a).
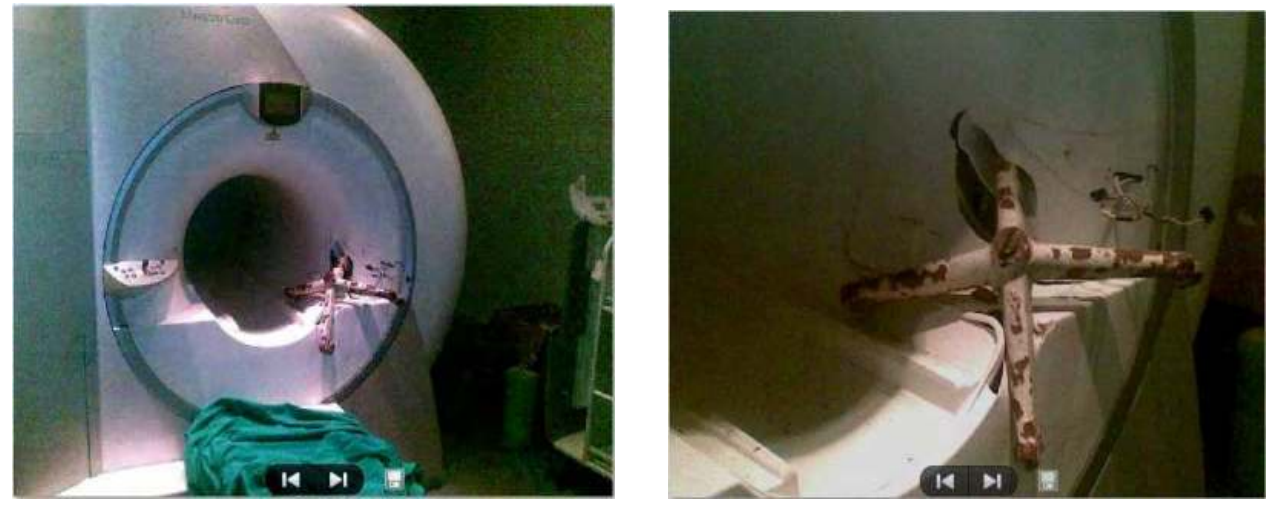

Fig. 5. Photographs of a hanger of saline physiology stucked to the MRI (Sezdi, 2009a)

"Risk Management" protocol within the scope of quality health care obliges to keep an absolute record of medical device accidents (Nobel, 1996). In order to prevent the repetition of these accidents, personnel training programs and security system are a contribution to the work of "patient safety", it can not be separated.

\section{The classification of clean rooms, particle measurements}

In hospitals, the operation rooms and intensive care rooms are known as clean rooms because it must have the high quality air without the dust and the particles. The clean rooms are closed places whose temperature, humidity, pressure and particles must be controlled.

In the clean room, the dust that is sourced from both the personnel and the patient and the machines, causes the risk of infection. Particularly, in the intensive care rooms for babies, the risk of infection is higher. By using the clean-air system, it is seen that the percent of 
infection risk decreases. But, this clean air system must be controlled by using the method of "the clean room classification" (Sezdi, 2009c).

Clean rooms in hospitals are divided into 2 groups in terms of particle concentrations. Class I rooms are areas that require high degree of hygienic conditions. These include:

- Operating rooms

- Sterilization rooms

- $\quad$ Sterile equipment storage rooms

- Intensive care patient rooms

- Newborn baby rooms

- Surgical department

- Patient rooms which is danger of infection

Class II rooms are areas that require normal hygienic conditions. These include:

- Patient rooms

- $\quad$ Emergency units

- Laboratories

- Caesarean section rooms

- Radiology, nuclear medicine treatment rooms

- Morgue and autopsy rooms

Operating rooms are divided into groups in itself as 1A and 1B. 1A-class operating rooms are operating rooms which require very high hygiene environment. In this type of operating rooms, air flow is done with laminar flow units which produce low turbulent air flow. The interventions in the Class1A-type operating room are as follows:

- Heart and vascular surgery

- Brain surgery

- Transplantation

- Bone marrow transplantation

- Orthopedic or interventions after accident

Class 1B operating rooms are used for interventions that do not require low-turbulent flow. The operations in the 1B-type operating rooms are as follows:

- Arthroscopy

- Thoracoscopy

- Laparoscopy

- Bronchoscopy

- Endoscopy

- Cardiac catheter examination

The classification of the operation room and the intensive care room is determined by the international standard of particle measurements. The related standard is ISO 146441:1999(E) "Cleanrooms and associated controlled environments Part 1: Classification of air cleanliness".

The main criteria for the classification of clean rooms is the particle dimension $(0,1 \mu \mathrm{m}$, $0,2 \mu \mathrm{m}, 0,3 \mu \mathrm{m}, 0,5 \mu \mathrm{m}, 1 \mu \mathrm{m}$ and $5 \mu \mathrm{m})$ and the particle concentration. In according to this 
standard, the mean particle concentration from each point must be equal to the limit particle concentration or lower.

The maximum permitted concentration of particles for each considered particle size is determined from the following equation (ISO 14644-1, 1999):

$$
C_{n}=10^{N} \times(0,1 / D)^{2,08}
$$

where

$\mathrm{C}_{\mathrm{n}}$ is the maximum permitted concentration (particles $/ \mathrm{m}^{3}$ of air)

$\mathrm{N}$ is the ISO classification number, which shall not exceed a value of 9 .

$\mathrm{D}$ is the considered particle size, in micrometers.

0,1 is a constant.

Table 1 presents selected particulate cleanliness classes and the corresponding particle concentrations.

\begin{tabular}{|c|c|c|c|c|c|c|}
\hline \multirow{2}{*}{$\begin{array}{l}\text { ISO } \\
\text { Classification } \\
\text { Number }(\mathbf{N})\end{array}$} & \multicolumn{6}{|c|}{$\begin{array}{l}\text { Maximum concentration limits (particles } / \mathrm{m}^{3} \text { of air) for particles equal to and } \\
\text { larger than the considered sizes shown below. }\end{array}$} \\
\hline & $0,1 \mu \mathrm{m}$ & $0,2 \mu \mathrm{m}$ & $0,3 \mu \mathrm{m}$ & $0,5 \mu \mathrm{m}$ & $1 \mu \mathrm{m}$ & $5 \mu \mathrm{m}$ \\
\hline ISO Class 1 & 10 & 2 & & & & \\
\hline ISO Class 2 & 100 & 24 & 10 & 4 & & \\
\hline ISO Class 3 & 1000 & 237 & 102 & 35 & 8 & \\
\hline ISO Class 4 & 10000 & 2370 & 1020 & 352 & 83 & \\
\hline ISO Class 5 & 100000 & 23700 & 10200 & 3520 & 832 & 29 \\
\hline ISO Class 6 & 1000000 & 237000 & 102000 & 35200 & 8320 & 293 \\
\hline ISO Class 7 & & & & 352000 & 83200 & 2930 \\
\hline ISO Class 8 & & & & 3520000 & 832000 & 29300 \\
\hline ISO Class 9 & & & & 35200000 & 8320000 & 293000 \\
\hline
\end{tabular}

Table 1. ISO classification numbers related to particle concentration (ISO 14644-1, 1999)

In clean rooms, making the control of the patient lying area such as operating table in operating room, patient beds in intensive care services, rather than controlling of HEPA filters is important. At that points all particles in the air must be sucked back to the ground and subdued.

For the particle measurements, a particle measurement test device is used. Measurements are taken from different points whose number is calculated from the square root of the area $\left(\mathrm{m}^{2}\right)$ of the clean room. For example, in a clean room of $25 \mathrm{~m}^{2}$, the measurements should be taken from 5 different points. The measurement results are analyzed by comparing the limit values in ISO 14644-1 standard.

Accordingly, although the clean room with laminar flow system should provide the conditions of ISO Class 3, the clean room with HEPA filter should provide them of ISO Class 5.

After validation, a full-fledged evaluation report including the main scheme and the sampling plan of clean rooms, measurement results and calibration dates of measurement devices, is prepared. 


\section{Radiation safety}

During radiation, if the prevention is insufficient, both the patient and the user are exposed with high value dose and they are affected from high dose badly. Radiation doses cause severe destruction on the skin and harm to human health depending on the level of dose.

The application of Radiation Safety Program is important in accordance with safety of both patient and user. The objective of Radiation Safety is to provide standardization to prevent radiation's ill effect. The International Commission on Radiation Protection (ICRP), the International Atomic Energy Agency (IAEA) and other various independent institutions have been making publications in relation to ionizing radiation protection for more than fifty years. Report 60 of the ICRP and the Basic Safety Standards that was published in the IAEA report have three basic principles related to the radiation protection (ICRP, 1991; IAEA, 1996).

For medical radiation application, the prevention method from radiation can be summarized as the following three headings:

- Justification: do not permit the non-benefit radiation. By considering the harmful results of radiation, the radiation with clear advantage is only accepted.

- Limitation: limitation of annual radiation dose. The annual radiation dose must not be exceed the limit value.

- Optimization: to expose possible minimum dose. Except for radiotheraphy radiation, the minimum dose is exposed to the person by considering the economic and social factors.

The main two important issues of radiation management are, in general, the implementation of a quality control program for usage of radiation and for monitoring the quantity of doses received by individual patients, and continuous training of the device users.

For manageability of the radiation protection process, in each institution of radiation, a radiation safety program and certain precautions for patients who are treated with radioactive materials in unusual cases, must be followed.

Under this program, radiation safety training should take place in a serious way. A radiation safety manual should be prepared and if needed, should be presented as a resource accessible.

A committee related to radiation safety should be established, additionally effective and efficient operation of this committee should be provided. Principles of radiation protection should be ascertained and a procedure for application should be established. It is essential to control whether safety rules are applied or not.

Working with radiation, precautions should be applied carefully. In the walls of the rooms where all the devices that work with X-ray tube, as a minimum $1.5 \mathrm{~mm}$ thick lead shielding material should be used. Lead apron must be used in scopy room and must be used during shooting. Lead aprons are made from 0,25 to $0,5 \mathrm{~mm}$ lead equivalent material. Lead aprons must be stored by hanging for not broken, never fold it. When working close to the X-ray beam, equivalent lead thickness of protective gloves should be $0,5 \mathrm{~mm}$. The doors must be kept closed during the shooting. 
For the National Radiation Safety Program, each foundation that is related to the radiation must be controlled.

\section{Electrical safety}

The electrical safety is essential in patient safety because of electrical shock. In cases of electrical shock, the important thing is the electrical current flowing from human's body. The current not voltage is often the source of injury or death.

When an electrical current flows through the human body the effect of current is influenced by two main factors. Firstly the amount of current and secondly the length of time that the current flows.

The effect of current on the human body can be given as below (Webster, 1992):

- $\quad 0,5-10 \mathrm{~mA}$ threshold of perception

- $\quad 6,0-50,0 \mathrm{~mA}$ let-go current

- $\quad$ 75,0 - 400,0 mA ventricular fibrillation

- 1-10 A myocardial contraction, burns and physical injury

When the electrical current exceeds a certain limit value, the electrical shock that are called as "macroshock" occurs. In macroshock, the effect of current starts with a slight feeling on the skin. By increasing the value of electrical current, muscle cramps and spasms, difficulty breathing, ventricular fibrillation, burns and death occur.

In the invasive techniques that reduce or eliminate the resistance of skin, the patient is unprotected against electrical shock. ECG electrodes reduce the skin resistance because of the gel between them and increase the risk of electrical shock. However, intravenous catheters serve as a good conductor mounted directly to the heart when the contrast agent is used. As a result of leakage currents, electrical shock is seen in patients with catheter and called as "microshock" (Barbosa et al., 2010; Osman et al., 1996; Sezdi, 2009b).

To prevent patients from electrical shock, the electrical safety measurements of the medical devices should be performed by considering their different electrical specifications that are expressed by standard symbols (Figure 6). Medical devices are classified as Class I and Class II according to their electrical specifications. Class I devices are provided with basic insulation. Class I equipment is fitted with a three core mains cable containing a protective earth wire. Exposed metal parts on Class I equipment are connected to this earth wire (Chakrabartty et al., 2010). Class I is the most common type.

Class II equipment is enclosed within a double insulated case and does not require earthing conductors. Class II equipment is usually fitted with a 2-pin mains plug. Class II or double insulated equipment can be identified by the Class II symbol on the cabinet (Chakrabartty et al., 2010).

Because some medical devices have applied part which is designed to come into physical contact with the patient, electrical specifications of applied parts must be known for safety testing (Backes, 2007). 


\begin{tabular}{|c|c|c|c|}
\hline 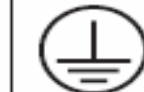 & Class I & & $\begin{array}{c}\text { Earth } \\
\text { Reference } \\
\text { point }\end{array}$ \\
\hline & Clars II & & $\begin{array}{c}\text { i.e. } \\
\text { "Conformité } \\
\text { Européenne" }\end{array}$ \\
\hline & $\begin{array}{c}\text { Type B } \\
\text { Applied Part }\end{array}$ & & $\begin{array}{l}\text { Defibrillation } \\
\text { proof typo B } \\
\text { Applied Part }\end{array}$ \\
\hline 11 & $\begin{array}{c}\text { Type BF } \\
\text { Applied Part }\end{array}$ & $\stackrel{\mathbf{N}}{\mathbf{N}}$ & $\begin{array}{l}\text { Defibrillation } \\
\text { proof type BF } \\
\text { Applied Part }\end{array}$ \\
\hline & $\begin{array}{c}\text { Type CF } \\
\text { Applied Part }\end{array}$ & -1 & $\begin{array}{l}\text { Defibrillation } \\
\text { proof type CF } \\
\text { Applied Part }\end{array}$ \\
\hline
\end{tabular}

Fig. 6. The most commonly used symbols for electrical specifications of devices (Backes, 2007).

F-Type Applied Part is electrically isolated from Earth. F-type applied parts are usually used as either type BF or type CF Applied Parts.

Type B Applied Part is usually Earth referenced. Type B applications can not be used for direct cardiac application.

Type BF Applied Part has a higher degree of protection against electrical shock. But like type B, they can not be used for direct cardiac application.

Type CF Applied Part has the highest degree of protection against electrical shock. They are suitable for direct cardiac application.

In order to control the electrical safety of medical devices, there are some standards that were produced by the International Electrotechnical Committee (IEC). These standards are IEC 60601 and IEC 62353. Although these standards have some differences about the measurement technique of earthbond and leakage current, both of them are used for electrical safety analyses of medical devices (IEC 60601-1; IEC 62353).

Earthbond measurements are performed to check the low resistance connection between the earth and any metal parts. The resistance is measured between two probes. The first probe is connected to the earth point and the other is connected to the metal parts of the medical device.

Leakage measurements are performed from 4 different sources (Backes, 2007). These are; Earth Leakage, Enclosure Leakage, Patient Leakage and Patient Auxiliary Leakage. In according to the IEC 60601-1, the limits of leakage currents for different type applied parts can be seen in Table 2 .

- Earth Leakage: It is the current flowing down the Earth conductor of the mains inlet lead (Figure 7). 


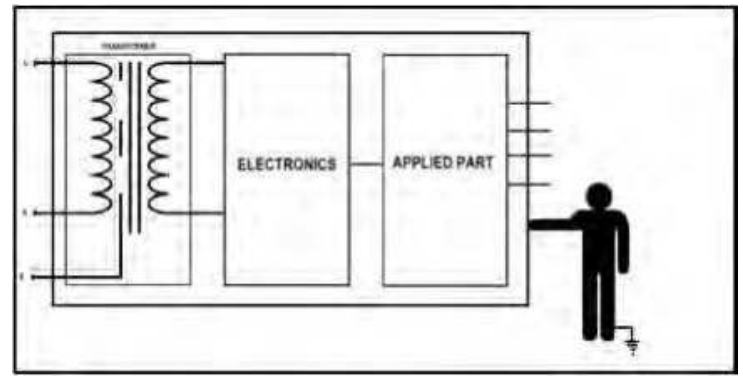

Fig. 7. Schematic diagram of earth leakage

- Enclosure Leakage: It is the current flowing to Earth through a person by touching the medical equipment (Figure 8).

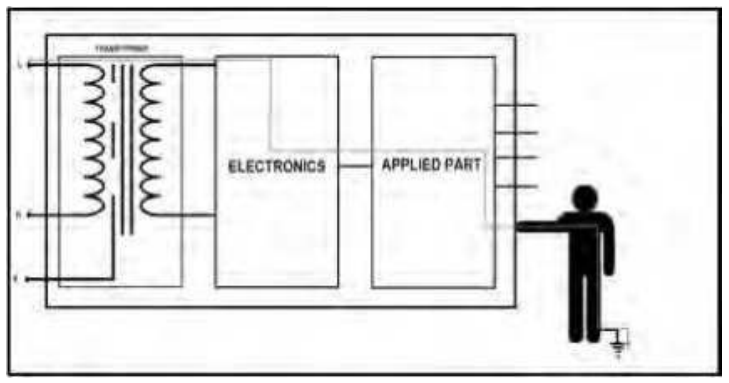

Fig. 8. Schematic diagram of enclosure leakage

- Applied Part or Patient Leakage: It is the current flowing through a person to Earth from the Applied Part or the current flowing from a person to Earth via the Applied Part (Figure 9).

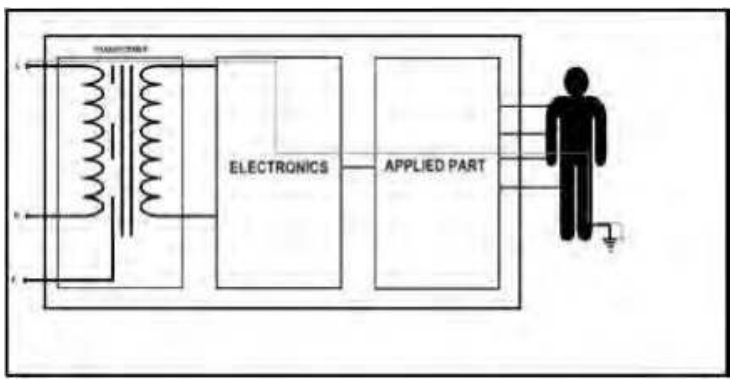

Fig. 9. Schematic diagram of patient leakage

- Patient Auxiliary Current: It is the current flowing between parts of the applied part through the patient (Figure 10). 


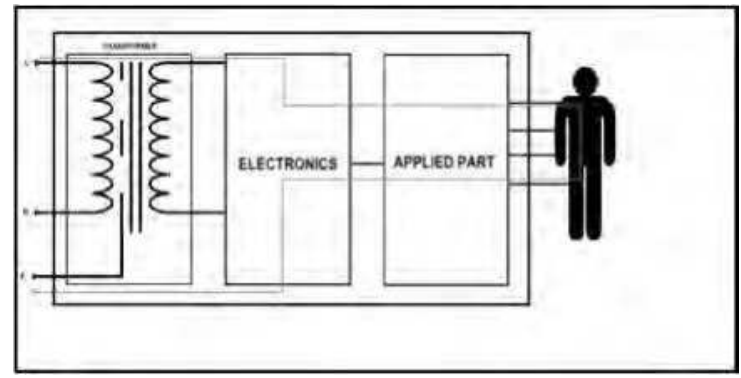

Fig. 10. Schematic diagram of patient auxiliary leakage

All leakage measurements are done by introducing conditions that could occur under normal use and under a single fault condition (SFC). The leakage tests are performed as follows:

1. Normal Supply Voltage

2. Normal Supply Voltage Open Neutral

3. Normal Supply Voltage Open Earth

4. Reversed Supply Voltage

5. Reversed Supply Voltage Open Neutral

6. Reversed Supply Voltage Open Earth

\begin{tabular}{|l|c|c|c|c|c|c|}
\hline & \multicolumn{2}{|c|}{$\begin{array}{c}\text { Type B } \\
\text { Applied Parts }\end{array}$} & \multicolumn{2}{c|}{$\begin{array}{c}\text { Type BF } \\
\text { Applied Parts }\end{array}$} & \multicolumn{2}{c|}{$\begin{array}{c}\text { Type CF } \\
\text { Applied Parts }\end{array}$} \\
\hline Leakage Current Type & NC & SFC & NC & SFC & NC & SFC \\
\hline Earth Leakage & $0,5 \mathrm{~mA}$ & $1 \mathrm{~mA}$ & $0,5 \mathrm{~mA}$ & $1 \mathrm{~mA}$ & $0,5 \mathrm{~mA}$ & $1 \mathrm{~mA}$ \\
\hline Enclosure Leakage & $0,1 \mathrm{~mA}$ & $0,5 \mathrm{~mA}$ & $0,1 \mathrm{~mA}$ & $0,5 \mathrm{~mA}$ & $0,1 \mathrm{~mA}$ & $0,5 \mathrm{~mA}$ \\
\hline Patient Leakage (dc) & $0,01 \mathrm{~mA}$ & $0,05 \mathrm{~mA}$ & $0,01 \mathrm{~mA}$ & $0,05 \mathrm{~mA}$ & $0,01 \mathrm{~mA}$ & $0,05 \mathrm{~mA}$ \\
\hline Patient Leakage (ac) & $0,1 \mathrm{~mA}$ & $0,5 \mathrm{~mA}$ & $0,1 \mathrm{~mA}$ & $0,5 \mathrm{~mA}$ & $0,01 \mathrm{~mA}$ & $0,05 \mathrm{~mA}$ \\
\hline Patient Auxiliary Cur. (dc) & $0,01 \mathrm{~mA}$ & $0,05 \mathrm{~mA}$ & $0,01 \mathrm{~mA}$ & $0,05 \mathrm{~mA}$ & $0,01 \mathrm{~mA}$ & $0,05 \mathrm{~mA}$ \\
\hline Patient Auxiliary Cur. (ac) & $0,1 \mathrm{~mA}$ & $0,5 \mathrm{~mA}$ & $0,1 \mathrm{~mA}$ & $0,5 \mathrm{~mA}$ & $0,01 \mathrm{~mA}$ & $0,05 \mathrm{~mA}$ \\
\hline
\end{tabular}

Table 2. Limits of leakage currents for different type applied parts (Backes, 2007)

The electrical safety measurements of the medical devices are performed by using an electrical safety analyzer. The analyzer has a software containing the standard of IEC 606011 or IEC 62353 , or both of them. When the electrical safety measurements are performed, the results are compared to the limit values of the international standards that are loaded in the analyzer and are printed as a report. The report gives the information about whether the device is appropriate to the international standard or not.

For electrical safety, all hospital staff (medical personnel, technical and biomedical staff, hospital management, and even patients) must take on the responsibility. Personnel should not use an extension cord to connect the medical device to the network, should notify the broken / cracked sockets and electric plugs to the relevant technical staff. Any electrical appliance should not be used without a ground connection. Particularly, electrically operated devices and electrical sockets in hospital should be tested in 1 time per year. 


\section{Performance measurements of medical devices}

Patient safety and the quality of medical technology are provided by the performance control of medical devices. Basically, if a sphygmomanometer (noninvasive blood pressure device) does not measure correctly, or an electrocardiography (ECG) does not draw the ECG trace sensitively, it can not be mentioned from the true diagnosis. Wrong diagnosis causes wrong treatment and in this point, some contraventions on patient safety begins. In Figure 11 and 12, the photographs of the performance measurements for the patient monitor, the defibrillator and the anesthesia machine can be seen as an example.
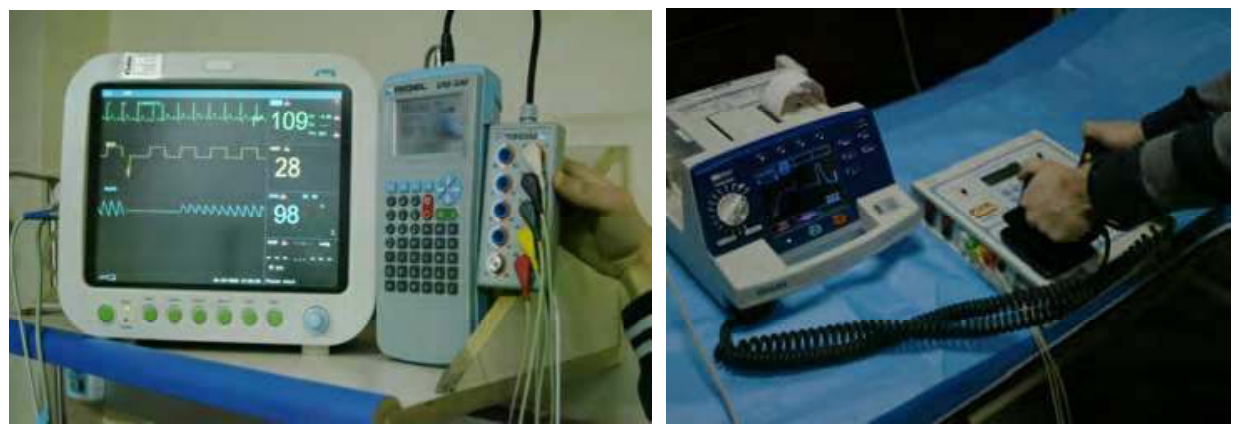

Fig. 11. The performance measurements of the patient monitor and the defibrillator

Performance measurement is the measurement of the accuracy of the medical device or the medical system by using the standard measurement system whose accuracy is known, and is the determination and the record of the deviations. In shortly, by the performance measurements, it is established whether the medical devices are appropriate to the international standards or not, and the problems are also determined if the device is not adequate to the international standards.

The objective of the performance measurement, is to be sure from the accuracy of the medical devices, to minimize the risks and to provide international standardization.

For performance measurements, respectively, the following procedures are observed.

- The medical equipment inventory of the hospital is prepared.

- The medical devices whose performance measurement is needed or not, are determined.

- $\quad$ Performance measurement intervals are determined.

- $\quad$ Performance measurement procedures and measurement forms are prepared.

- Performance measurements are performed in accordance with procedures at the location of the devices and the measurement forms are filled.

- The devices are labeled with the green or red sticker to highlight the performance measurement result.

- Performance measurement certificates are prepared and measurement results are interpreted according to the acceptance criteria in the international standards.

- Performance measurement certificates are archived. 


\subsection{Medical equipment inventory}

All medical devices in a hospital are listed in an inventory. The devices are labeled by using Biomedical Code. Each Biomedical Code should consist of both Universal Medical Device Nomenclature Codes (UMDNS) to define the device and the sign of location. For example the code of ICU 11132001 means the first defibrilator in intensive care unit. The code of OPR 11132001 means the first defibrilator in operation room.

\subsection{Performance measurement intervals}

Performance measurements are not performed for some medical devices that do not have any risk on patients for example nebulizator or ache pump. The technological medical systems including risk are classified as 3 groups. These are:

- High-risk system; They are intensive care, surgical, diagnostic and treatment systems. Their failure or misuse may cause damage to the patient or staff.

- Moderate-risk systems; In case of malfunction, improper use or lack of them, several problems that do not harm the patient or staff seriously may occur in patient care.

- Low-risk systems; The problems about patient care is minimum.

The performance measurement periods are determined by experienced users by considering the device features and the usage conditions. Performance measurement period of devices is calculated with the "Device Management Coefficient" which is used in "Clinical Equipment Management" standards in the "Technology \& Safety Management" series developed by the Joint Commission (Fennigkoh et al. 1989). The equation of the "Device Management Coefficient" is shown below.

Device Management $=$ Device Function + Device Risk + Device Preventive Maintenance (2)

$$
\text { Coefficient Point Point Point }
$$

According to the standards, Device Management Coefficient can be maximum of 20 and the devices with 12 or more coefficient are incorporated into the plans of performance measurements (Fennigkoh et al. 1989). If the Device Management Coefficient is greater than 16 , the device must be controlled every 6 months.

Device Function Point: It is scored by considering the importance of their function (Table 3)

\begin{tabular}{|c|l|}
\hline Point & Device function \\
\hline 10 & Life Recovery Devices \\
\hline 9 & Surgical and Intensive Care Devices \\
\hline 8 & Physical Therapy Devices \\
\hline 7 & Surgical and Intensive Care Patient Monitoring Devices \\
\hline 6 & Other Physiological Monitors \\
\hline 5 & Analytical Laboratory Devices \\
\hline 4 & Laboratory Equipment and Supplies \\
\hline 3 & Computers \\
\hline 2 & Devices that belong to the patients \\
\hline 1 & Other devices \\
\hline
\end{tabular}

Table 3. The points for device function (Fennigkoh et al. 1989) 
Device Risk Point: Medical devices have different risks (Table 4) because their absence or failure may cause different problems in patient care.

\begin{tabular}{|c|l|}
\hline Point & Device risk \\
\hline 5 & Patient death \\
\hline 4 & Patient or staff injury \\
\hline 3 & Wrong diagnosis or treatment \\
\hline 2 & Diagnosis and treatment delays \\
\hline 1 & Risk not important \\
\hline
\end{tabular}

Table 4. The points for device risk (Fennigkoh et al. 1989)

Device Preventive Maintenance Point: Device preventive maintenance points (Table 5) are determined by considering following cases.

- Relevant codes and standards,

- The risks of the device,

- The procedures and test ranges in the device's user and service books,

- The device malfunctions occurred before,

- The service and media properties,

- The usage frequency of the device,

- The device status (old or new, the design problems).

\begin{tabular}{|c|l|}
\hline Point & The order of importance \\
\hline 5 & Very important \\
\hline 4 & Moderately important \\
\hline 3 & Less important \\
\hline 2 & The least important \\
\hline 1 & Minimally important \\
\hline
\end{tabular}

Table 5. The points for preventive maintenance importance of device (Fennigkoh et al. 1989)

For the calculation of the "Device Management Coefficient", defibrillator device can be given as an example. Firstly, it's function score can be defined as 10 points because it is used for life recovery. The risk score of it can be defined as 5 points because the patient injury or death will be resulted if the device is corrupted or malfunctioning. Finally, the score of the equipment preventive maintenance requirements can be accepted as 4 points by considering the usage frequency of the devices and the risk of breakdown. With the total 19 points, it is decided that the performance measurements of defibrillators should be done every 6 months. In this manner, to determine which devices are taken into the performance measurement system, each medical device is separately handled and the points for all devices are calculated.

\subsection{Performance measurement procedures}

Measurements are done in accordance to the international standards. Performance measurements are generally performed by using IPM (Inspection and Preventive Maintenance) system procedures that were prepared by Emergency Care Research Institute (ECRI). The principle is to control all parameters of a medical device. The procedures consist 
of the test steps for both physical and parametrical control. In Table 6, the measurement parameters of some medical devices are listed for illustration.
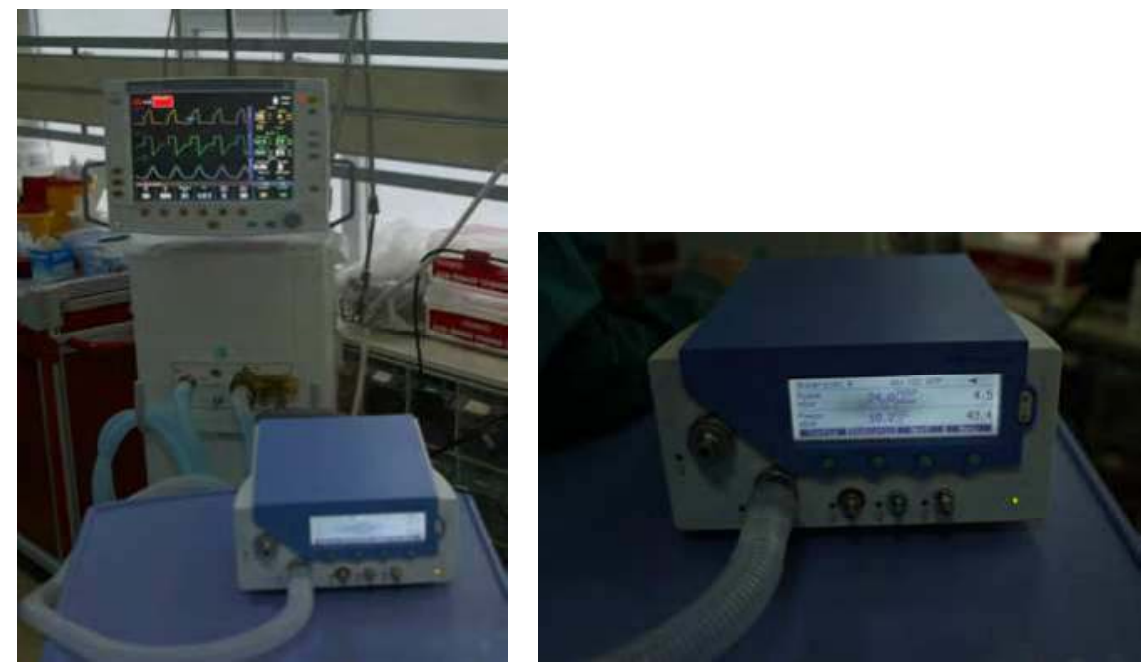

Fig. 12. The performance measurement of the anesthesia machine

The measurement procedures also consist of acceptable criterias. The results of measurements are interpreted in according to the acceptable limit values. The medical devices whose measurement results are in the range of acceptable values are appropriate to the international standards and are labelled with yellow sticker. It means that the medical device can be used. The medical devices whose measurement results are out of the range of acceptable values are inappropriate to the international standards and are labelled with red sticker. Red sticker means that the medical device should not be used and the device should be controlled by technical personnel or related technical service.

\subsection{Performance measurement certificates}

The results of performance measurements are given in the calibration certificates. The information to be included in a performance measurement certificate is given below.

- The date of performance measurement,

- The next performance measurement date,

- Situation of the measurement,

- Identity information of the institution performing the performance measurement,

- Information of the test equipment used,

- Environmental conditions at the time of measurement,

- Information obtained during the performance measurement,

- Verification measurements and corrections.

There are some important issues that must be considered during the implementation of the performance measurement method specified in the measurement instructions. They are given below. 


\begin{tabular}{|c|c|}
\hline Medical Device & Parameters \\
\hline \multirow[t]{8}{*}{ PATIENT MONITOR } & Electrical Safety Tests \\
\hline & Heart Rate - Fibrillation Arrhythmia \\
\hline & Respiration Rate - Apnea \\
\hline & Invasive Blood Pressure \\
\hline & Noninvasive Blood Pressure \\
\hline & Cardiac Output \\
\hline & Oxygen Saturation Concentration \\
\hline & Temperature \\
\hline \multirow[t]{10}{*}{ ANESTHESIA MACHINE } & Electrical Safety Tests \\
\hline & Gas Concentration (Isoflourane,......) \\
\hline & Tidal Volume \\
\hline & Minute Volume \\
\hline & Inspiration Time \\
\hline & Expiration Time \\
\hline & I/E Ratio \\
\hline & PEEP \\
\hline & Mean and Maximum Pressure \\
\hline & Oxygen Concentration \\
\hline \multirow[t]{5}{*}{ ELECTROCARDIOGRAPHY } & Electrical Safety Tests \\
\hline & Linearity Test \\
\hline & Sensitivity Test \\
\hline & $1 \mathrm{mV}$ Pulse Test \\
\hline & Paper Speed Test \\
\hline \multirow[t]{5}{*}{ DEFIBRILLATORS } & Electrical Safety Tests \\
\hline & Energy Measurement \\
\hline & Charge Time Test \\
\hline & Battery Test \\
\hline & ECG and Arrhythmia Simulation \\
\hline
\end{tabular}

Table 6. The measurement parameters of some medical devices

- $\quad$ Performance measurements should be done by trained personnel.

- The international traceability of the test equipment must be ensured.

- The error rate used in the measurement process should be known.

- The accuracy of the test equipment must be very small than the accuracy of the device which is tested.

- Technical specifications of the device must be determined.

- The environmental conditions such as heat, moisture, vibration, dust, electromagnetic field strength, temperature change rate etc. should be checked during the performance measurements. 
- Measuring range must be identified and measurements must be screened in this range,

- The repeatability of the measurements must be provided.

\section{Conclusion}

As a result, it is seen that one of the important components of patient safety is medical device safety. By increasing medical device safety, patient safety increases.

By taking the necessary measures related to all considerations mentioned in the above sections;

- Prevention of medical accidents that may occur in the health establishment,

- Reducing the risk of infection,

- Ensuring the accuracy of medical devices,

- Routine controlling of medical devices,

- Increasing of both employee and patient satisfaction, are possible.

Therefore, the "patient safety" is under control as a result of good management of medical technology.

\section{References}

AAMI, (1995). Sterilization Part 1. Sterilization of Healthcare Facilities. Sterilization Part 2. Hospital Eqipment and Industrial Process Control, Association for the Advancement of Medical Instrumentation, USA

AMN Healthcare, (2008). Fire Starter. in Action Steps, (2008)

ANSI AAMI ST79, (2006). Comprehensive Guide to Steam Sterilization and Sterility Assurance in Health Care Facilities. Association for the Advancement of Medical Instrumentation, ISBN 1-57020-256-7, USA

Avitall, B., Khan, M., Krum, D., Jazayeri, M., \& Hare, J. (1993). Repeated use of ablation catheters: A prospective study. Journal of American College of Cardiology, Vol.22, No.5, (1993), pp. 1367-1372

Backes, J. (2007). A Practical Guide to IEC 60601-1. Rigel Medical, United Kingdom, (2007)

Barbosa, A.T.R., Iaione, F., \& Spalding, L.E.S. (2010). In a hospital: an electrical safety and information system. 32nd Annual International Conference of the IEEE EMBS, (2010), pp. $4427-4430$

Bassen, H.I. (1998). COMAR technical information statement: Radiofrequency interference with medical devices. IEEE Engineering in Medicine and Electronics Engineers, Vol.17, No.3, (1998), pp. 111-114

Brennan, T.A., Leape L.L., Laird N.M., \& Hebert, L. (1991). Incidence of adverse events and negligence in hospitalized patients: Results of the Harward Medical Practice Study. N Engl J Med., Vol.324, No.6, (1991), pp. 370-376

Buchdid Amarente, J.M., Toscana C.M., Pearson M.L., Roth, V., \& Jarvis W.R. (2008). Reprocessing and reuse of single-use medical devices used during hemodynamic procedures in Brazil: A widespread and largely overlooked problem. Infect Control Hospital Epidemiol, Vol.29, No.9, (2008), pp. 854-858

Carranza, N., Febles, V., Hernandez, J.A., Bardasano, J.L., \& Monteagudo, J.L. (2011). Patient safety and electromagnetic protection: A review. Health Physics, Vol.100, No.5, (2011), pp. 530-541 
Carol, R. (2003). FDA works to reduce preventable medical device injuries. FDA Consumer, Vol. 37 (4), July (2003)

Chakrabartty, A., Panda, R. (2010). Criticality of electrical safety for medical devices. Proceedings of 2010 International Conference on Systems in Medicine and Biology, (2010), pp. $212-216$

Day, P. (2004). What is the evidence on the safety and effectiveness of the reuse of medical devices labelled as single-use only? New Zealand Health Technology Assessment, Vol.53, (2004)

Dubois, V. (2002). Sterilization techniques for medical instrumentation in health care facilities. Vide-Science Technique et Applications, Vol.57, (2002), pp. 85-91

Emergency Care Research Institute (2006). FDA issues statement on reuse of single-use devices. FDA Normal Priority Medical Device Alert, (2006).

Fennigkoh, L., Smith, B. (1989). Clinical equipment management. JCAHO Plant, Technology $\mathcal{E}$ Safely Management Series (2), (1989), pp. 5-14

FDA (1997). A primer on medical device interactions with magnetic resonance imaging systems. FDA's Good Guidance Practices, (February 1997)

FDA (2000). FDA releases final guidance on the reprocessing and reuse of single-use devices. Medical Device Reporting, No. 31, (2000)

Gilligan, P., Somerville, S., \& Ennis, J.T. (2000). GSM cell phones can interfere with ionizing radiation dose monitoring equipment. The British Journal of Radiology, Vol.73, (2000), pp. 994-998

Hailey, D., Jacobs, P.D., Ries, N.M., \& Polisena, J. (2008). Reuse of single use medical devices in Canada: Clinical and economic outcomes, legal and ethical issues, and current hospital practice. International Journal of Technology Assessment in Health Care, Vol.24, No.4, (2008), pp. 430-436

Hans, N. \& Kapadia F.N. (2008). Effects of mobile phone use on specific intensive care unit devices. Indian Journal of Critical Care Medicine, Vol.12, No.4, (2008), pp. 170-173

Henney, J.E. (2000). FDA's proposed strategy on reuse of single use devices. Journal of the American Medical Association, Vol.283, No.1, (January 2000), pp. 46

Hijazi, R. (2011). The impact of medical devices on patient health. Journal of Clinical Engineering, (July/September 2011), pp. 105-108

IAEA (1996). International Basic Safety Standards for Protection against Ionizing Radiation and for the Safety of Radiation Sources. IAEA Safety Series 15, ISBN 92-0-104295-7, Vienna, Austria

ICRP (1991). 1990 Recommendations of the international commission on radiological protection. ICRP Publication 60, Annals of the ICRP, Vol.21, No.1-3, (1991)

IEC 60601-1 (2005). Medical Electrical Equipment-General Requirements of Safety. International Electrotechnical Commission (IEC), (2005)

IEC 62353 (2007). Medical Electrical Equipment-Recurrent Test and Test after Repair of Medical Electrical Equipment. International Electrotechnical Commission (IEC), (2007)

ISO 14644-1:1999 (1999). Cleanrooms and associated controlled environments- Part 1: Classification of air cleanliness, International Standardization for Organization, (1999)

Kelkar, U., Bal, A.M., \& Kulkarni, S. (2004). Monitoring of steam sterilization process by biologic indicators-a necessary surveillance tool. American Journal of Infection Control, (2004), pp. 512-513 
Koh, A. (2005). Current practices and problems in the reuse of endoscopic single-use devices in Japan. American Journal of Infection Control, Vol.33, No.5, (2005), pp. 156

Lawrentschuk, N., \& Bolton, D.M. (2004). Mobile phone interference with medical equipment and its clinical relevance: a systematic review. The Medical Journal of Australia, Vol.181, No.3, (2004), pp. 145-149

McDermott, C. (2010). Regulations that impact disinfection and sterilization processes: ALPHA Patrol: Keeping health care safe for everyone. Perioperative Nursing Clinics, Vol.5, (2010), pp. 347-353

Nobel, J.J. (1996). Medical device accident reporting: does it improve patient safety? Stud Health Technol Inform, Vol.28, (1996), pp. 29-35

Northrup, S.J. (2000). Reprocessing single-use devices: An undue risk. Medical Device Manufacturers Association, (2000)

Osman, M.A., Todorova, A., \& Samra A.H. (1996). Electrical safety in medical institutionsNeutral electric potentiality system in hospitals. Proceedings of IEEE Southeastcon 97 Conference on Engineering the New Century, (1996), pp. 304-306

Quirk, M. (2002). Most Us hospitals avoid reuse of single-use devices. The LANCET Infectious Diseases, Vol.2, (December 2002), pp. 714

PMDA (2006). Effects on implantable medical devices/cardiac pacemakaers and cardioverter defibrillators) by new system mobile phone terminals. PMDA Pharmaceuticals and Medical Devices Safety Information, No.226, (2006), Tokyo, Japan

Popp, W., Rasslan, O., Unahalekhaka, A., \& Brenner, P. (2010). What is the use? An international look at reuse of single-use medical devices. International Journal of Hygiene and Environmental Health, Vol.213, (2010), pp. 302-307

Pressly, N. (2000). FDA warns about EMI risk with telemetry systems. FDA User Facility Reporting Bulletin, (2000)

Rados, C. (2004). FDA works to reduce preventable medical device injuries. FDA Consum. No. 37(4), (2004)

Rice, L.R.H., Albertson, L.V.E., Anderson, P., \& Day, M. (2009). Reuse of single -use critical medical devices. The Official Journal of The Society of Gastroenterology Nurses and Associates, Vol.32, No.3, (2009), pp. 228-229

Rizzo, J., Bernstein, D., \& Gress, F. (2000). A performance, safety and cost comparison of reusable and disposable endoscopic biopsy forceps: a prospective, randomized trial. Gastrointestinal Endoscopy, Vol. 51, No. 3, (2000), pp. 257-261

Rutala, W.A., \& Weber, D.J. (2004). Disinfection and sterilization in health care facilities: What clinicians need to know. Healthcare Epidemiology, Vol.39, (2004), pp. 702-709

Sawyer, D. (1997). An introduction to human factors in medical devices. U.S. Department of Health and Human Services, Food and Drug Administration, (1997).

Selvey, D. (2001). Medical Device Reprocessing Is it good for your organization? The FDA Guidance Document, (2001)

Sezdi, M. (2009a). The effects of medical device accidents and user errors to patient safety. Proceedings of 1st. International Conference on Patient Rights, (November, 2009)

Sezdi, M. (2009b). Is it possible that the death reason of a catheterized patient is the leakage current? Proceedings of 1st. International Conference on Patient Rights, (November, 2009)

Sezdi, M. (2009c). Particle measurement errors in intensive care units. Proceedings of $3^{\text {th }}$ International Conference on Quality in Healthcare Accreditation and Patient Safety, (2009) 
Tan, K.S., Hinberg, I., \& Wadhwani, J. (2001). Electromagnetic interference in medical devices: Health Canada's past and current perspectives and activities. Journal of IEEE Electromagnetic Compatibility, Vol. 2, (2001), pp. 1283-1288

Webster, J.G. (1992). Medical Instrumentation Application and Design (2nd edition), Houghton Mifflin Company, ISBN 0-395-59492-8, Boston, USA

Yoleri, G. (2011). Technical and Biological Performance Tests for Autoclave Units (Master Thesis), Istanbul University, Istanbul, Turkey

Zimerman, L.I., Cenci, F., \& Streck E.E. (2003). The effects of multiple reprocessing of radiofrequeny ablation catheters on their electrical integrity. Progress in Biomedical Research, Vol.8, No.2, (2003), pp. 116-118 


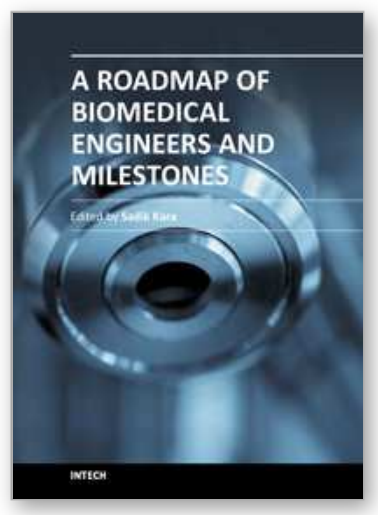

\author{
A Roadmap of Biomedical Engineers and Milestones \\ Edited by Prof. Sadik Kara
}

ISBN 978-953-51-0609-8

Hard cover, 230 pages

Publisher InTech

Published online 05, June, 2012

Published in print edition June, 2012

This book is devoted to different sides of Biomedical Engineering and its applications in science and Industry. The covered topics include the Patient safety in medical technology management, Biomedical Optics and Lasers, Biomaterials, Rehabilitat, Ion Technologies, Therapeutic Lasers \& Skin Welding Applications, Biomedical Instrument Aopplication and Biosensor and their principles.

\title{
How to reference
}

In order to correctly reference this scholarly work, feel free to copy and paste the following:

Mana Sezdi (2012). Medical Technology Management and Patient Safety, A Roadmap of Biomedical Engineers and Milestones, Prof. Sadik Kara (Ed.), ISBN: 978-953-51-0609-8, InTech, Available from: http://www.intechopen.com/books/a-roadmap-of-biomedical-engineers-and-milestones/patient-safety-inmedical-technology-management

\section{INTECH}

open science | open minds

\author{
InTech Europe \\ University Campus STeP Ri \\ Slavka Krautzeka 83/A \\ 51000 Rijeka, Croatia \\ Phone: +385 (51) 770447 \\ Fax: +385 (51) 686166 \\ www.intechopen.com
}

\author{
InTech China \\ Unit 405, Office Block, Hotel Equatorial Shanghai \\ No.65, Yan An Road (West), Shanghai, 200040, China \\ 中国上海市延安西路65号上海国际贵都大饭店办公楼 405 单元 \\ Phone: +86-21-62489820 \\ Fax: +86-21-62489821
}


(C) 2012 The Author(s). Licensee IntechOpen. This is an open access article distributed under the terms of the Creative Commons Attribution 3.0 License, which permits unrestricted use, distribution, and reproduction in any medium, provided the original work is properly cited. 